\title{
Induction Motor Stator Fault Classification Using PCA-ANFIS Technique
}

\author{
Ayodele Isqeel Abdullateef", Mohammed Faiz Sanusi, Olabanji, Sunday Fagbolagun \\ Department of Electrical and Electronics Engineering, University of Ilorin, Nigeria \\ *Corresponding author: abd_lateef.aii@unilorin.edu.ng, Tel: +2348086215103
}

\begin{abstract}
Induction motors are used commonly for industrial operations due to their ease of operation coupled with ruggedness and reliability. However, they are subjected to stator faults which result in damage and consequently revenue losses. The classification of stator fault in a three-phase induction motor based on Adaptive neuro-fuzzy inference system (ANFIS) in combination with Principal Component Analysis (PCA) is proposed in this study. A burnt motor was redesigned and rewound while data acquisition was developed to acquire the current and vibration data needed for the fault classification. The data feature extraction for the fault classification was carried out by PCA while backpropagation and the least-squares algorithms were used for the training of the data. Three principal components, which severs as input for the ANFIS, were used to represent the entire data. The ANFIS was tested under four different paradigms, while the membership function type and epoch number were changed at each instant. The ANFIS model based on the triangular membership function and 10 epoch number was found appropriate and used, bringing the accuracy of the model to over 99\% with the lowest ANFIS training RMSE error of $1.1795 \mathrm{e}^{-6}$. The ANFIS validation results of the fault classification show that the results are accurate, indicating that the PCAANFIS technique is applicable in fault diagnosis and classification of stator faults in induction motors.
\end{abstract}

Keywords: Stator fault, three-phase induction motor, Classification, Adaptive Neuro-fuzzy Inference System, Principal Component Analysis (PCA).

Article History: received 11 February 2020; accepted 30 March 2020; published 25 April 2020.

C 2020 Penerbit UTM Press. All rights reserved

\section{INTRODUCTION}

Induction motors are one of the most widely used electrical machines in the industries because of their low cost, ruggedness, low maintenance and reliability. However, despite their reliability, they are still very susceptible to failures such as stator faults which accounts for $30-40 \%$ of failures in induction motors and from which stator winding failure is the most common [1]. When these faults occur and are undetected early enough, they lead to severe damage of the machine and a high loss especially in the industries where an abrupt stop in operation and machine downtime constitutes a huge loss of revenue. Therefore, early detection of this fault is of importance in order to reduce the extent of damage incurred.

Usually, fault detection in induction motors is carried out manually whenever the circuit breaker or fuse which protects the motor is cut off or during maintenance. Thus, to reduce the cost of repair and replacement, condition monitoring or real-time monitoring of the motor is necessary. Condition monitoring is the process of observing a parameter or parameters in machinery for the purpose of identifying changes that could indicate a developing fault. The advantages of condition monitoring in machines including but not limited to an increase in machine availability, operating efficiency, reduction in overall maintenance cost and safety. In addition, it reduces consequential damages, spare parts inventories, replacements and increases lifespan. An effective condition monitoring scheme provides warning and predicts the faults at the early stages before the machine is damaged. It also obtains information on the machine in the form of data, which is processed through various techniques for necessary actions from the operators before it catastrophically fails. However, condition monitoring needs constant human interpretation.

Recently, a number of soft computing diagnostic techniques such as Neural network, expert system, adaptive neuro-fuzzy inference system, genetic algorithm and fuzzy logic have been proposed to identify and automate the diagnostic process. These techniques have become popular and widely used among other conventional techniques because they are tolerant of imprecision, uncertainty, partial truth and approximations. Moreover, they are easy to modify, extend and thus improve their performance [2]. For instance, Artificial Intelligence-based stator winding fault estimation in a three-phase induction motor using the fuzzy logic system has been proposed [3]. The study detects the short-circuit fault in a three-phase induction motor based on the magnitude of the stator current. The system makes use of knowledge-based rules, thus, eliminating the need for detailed modelling. Rodríguez and Arkkio [4] proposed the fuzzy logic for the detection of stator winding fault in an induction motor. The RMS values of the stator three-phase current and the variance were applied as the input of the developed fuzzy logic model under different load profiles. 
The developed fuzzy model recorded high accuracy in the detection of the motor condition in the presence of noise. Martins, et al. [5] proposed an unsupervised neuralnetwork-based algorithm for on-line diagnosis of threephase induction motor stator fault using the stator threephase current components as the input parameters. The principal components of the stator current were extracted using a Hebbian based unsupervised neural network. This approach was used to make decisions on the location of the fault.

A neural network approach for the automatic detection and location of an inter-turn short circuit fault in the stator windings of an induction motor has been proposed [6]. The backpropagation technique was used to train the input data to the neural network which was acquired from the phase shift between the line current and the phase voltage. The output of the network is set to either a 'one' or a 'zero' whenever a short circuit fault is detected on any of the three phases.

Adaptive Neuro-Fuzzy Inference System (ANFIS) is another soft computing technique that has been widely used in motor faults classification. This is not unconnected with the fact that it integrates both the neural network and fuzzy logic [7]. Besides, it does not involve mathematical modelling and primary knowledge of the motor and its performance and accuracy can be improved when combined with other methods [8]. Dash and Subudhi [9] proposed the use of the ANFIS system to detect stator inter-turn fault. The study compared the ANFIS performance with a multi-layer perceptron neural network (MLPNN). The fault detection and location are based on monitoring the three-phase shifts between the line currents and the phase voltage of the machine.

Furthermore, Jose and Jose [10] made use of Park's Vector approach employing Fuzzy logic and Adaptive Neuro-Fuzzy Inference System (ANFIS) to diagnose induction motor faults. The study carried out different simulations corresponding to some faults like stator open phase and short-circuit faults. Yilmaz and Ayaz [7] proposed an ANFIS system to detect a bearing fault in induction motors. The study used three ANFIS systems that take current, temperature and vibration data as inputs and also the condition of the motor as the output. The three ANFIS systems gave good performances but the best performance was achieved when the three signatures are used simultaneously. Other proposed studies on the detection of induction motor faults using the soft computing technique are [11]-[14]. Generally, the data used in these techniques require feature extraction in order to avoid dimensionality during the process of learning.

One of the methods used in feature extraction is Principal Component Analysis (PCA). It has been applied in combination with ANFIS in the measurement system for monitoring product quality in a coating industry, a high training accuracy and lower training time was achieved compared to ordinary ANFIS [15]. The hybrid PCAANFIS was also employed in Modelling the relationship between ground surface settlements induced by shield tunnelling and the operational and geological parameters [16]. However, the application of PCA in the field of machine fault analysis is still very few. In this paper, the integration of PCA and ANFIS is proposed for the classification of stator faults of an induction motor. The PCA is selected for the feature extraction process due to its reliability in the extraction of pertinent features and also due to its non-complex form. The ANFIS is then used as a classifier due to its high learning accuracy and scalability. [17].

\section{METHODOLOGY}

\subsection{Data Acquisition}

The data used in this study was acquired from experimental set up in the laboratory at the Department of Electrical and Electronics Engineering, University of Ilorin. The major components of the experiment include a three-phase induction motor with extended stator windings terminals for fault simulation, hall effect sensors (ACS712) for stator current data acquisition, a piezoelectric sensor for vibration data and Arduino Uno board. The setup is as shown in Figure 1. The types of fault considered are the stator inter-turn faults on each phase and phase to phase short circuit faults. A program was written in the Arduino IDE using the $\mathrm{C}++$ programming language for the microcontroller to read data from the sensors. The system acquires both the motor stator currents and vibration data at a sampling rate of $300 \mathrm{~Hz}$. Data acquired under each fault condition and normal condition were then stored and used for the fault classification in this study. The development of data acquisition details can be found in [18].

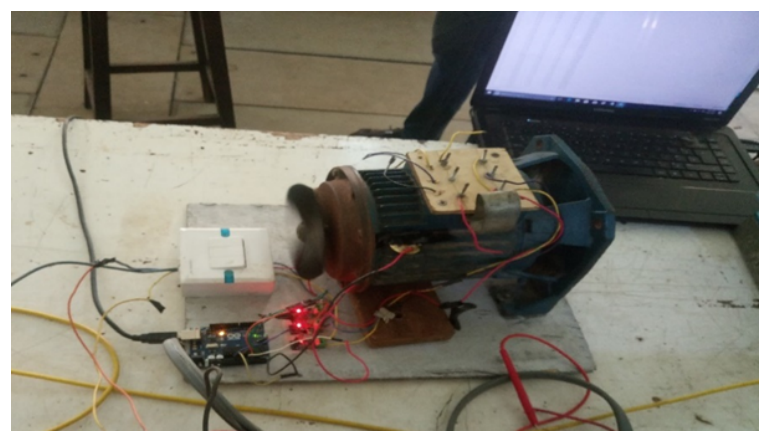

Figure 1. Experimental Setup

\subsection{Feature Extraction}

The large quantity of data acquired from the current and vibration sensors are ordinarily of high dimensionality and consists of noise and redundant features. The application of these raw data to the classification model will greatly reduce the accuracy of the classifier. Therefore, feature extraction of the data was carried out in order to eliminate the noise and select the significant and pertinent features for effective fault classification performance. This was achieved using PCA. The central idea is to reduce the dimensionality of a data set such that it contains a lot of correlated variables while retaining as much as the variations present in the original data set. This is achieved by transforming the original data to a new set of variables, the Principal Components (PCs) which are uncorrelated and ordered in such a way that the initial few retain most of the variation present in the original data [19]. PCA is 
able to obtain the main directions of the original data sample on the space-vector [5][20]. The PCA process flow chart is depicted in Figure 2.

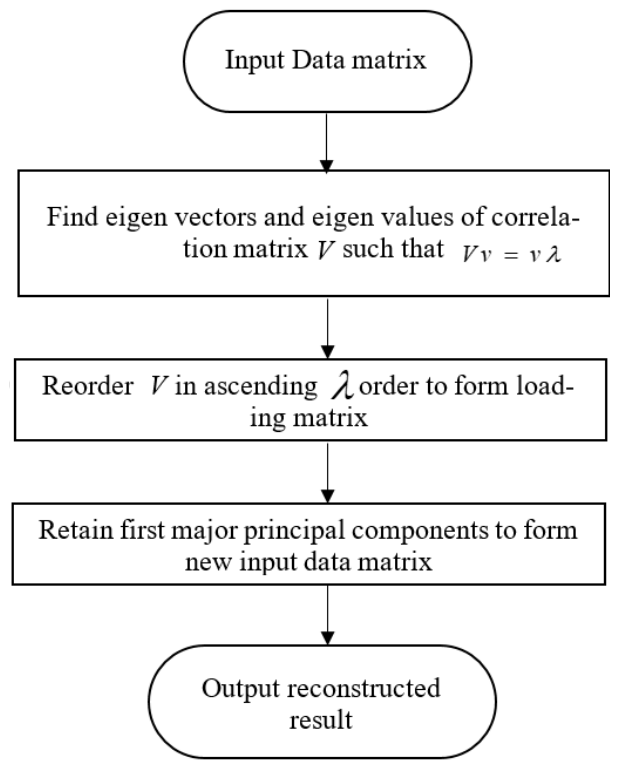

Figure 2. PCA Flowchart

The data are represented in matrix form as expressed in equation 1 with the first three columns representing the stator currents and the last column representing the acquired vibration data.

$$
A=\left[\begin{array}{cccc}
i_{a}\left(t_{0}\right) & i_{b}\left(t_{0}\right) & i_{c}\left(t_{0}\right) & v\left(t_{0}\right) \\
i_{a}\left(t_{0}+\Delta t\right) & i_{b}\left(t_{0}+\Delta t\right) & i_{c}\left(t_{0}+\Delta t\right) & v\left(t_{0}+\Delta t\right) \\
: & : & : & : \\
: & : & : & : \\
i_{a}\left(t_{0}+(n-1) \Delta t\right) & i_{b}\left(t_{0}+(n-1) \Delta t\right) & i_{c}\left(t_{0}+(n-1) \Delta t\right) & v\left(t_{0}+(n-1) \Delta t\right)
\end{array}\right]
$$

The number of rows of matrix $A$ is the number of significant samples under study which in this case, consists of the three-phase stator currents and the vibration signal. The first sample of matrix $A$ will be $\left[i_{a}\left(t_{0}\right) i_{b}\left(t_{0}\right) i_{c}\left(t_{0}\right) v\left(t_{0}\right)\right]$

where $t_{0}$ represents the initial time and $\Delta t$ represents the time interval. Linearly transforming the matrix $A$ into a new matrix $B$ of equal dimension $m \times n$, as shown in equation (2).

$$
B=Z * A
$$

where, $Z$ is a matrix of dimension $m \times m$.

Normalisation is a step of the PCA technique where the mean of the original data matrix is calculated and subtracted from the mean for calculating the PCs as shown in equation 3 [21].

$$
\operatorname{Mean}(\mathrm{m})=\frac{1}{N} \sum_{n=1}^{N} A[m, n]
$$

the covariance matrix of $A$ with dimension $m \times m$ is expressed as

$$
C_{A}=A * \frac{A^{T}}{(n-1)}
$$

Each element of the covariance matrix $C_{A}$ represents all the possible pair of covariance and all diagonal elements represents the variance and the non-diagonal elements of the matrix are the covariance [21].

The value of $Z$ has to be such that the covariance matrix $C_{B}$ becomes a diagonal matrix as expressed in equations 5.

$$
\begin{gathered}
C_{B}=B * \frac{B^{T}}{(n-1)}=\frac{(Z A)\left(A^{T} * Z^{T}\right)}{(n-1)} \\
C_{B}=\frac{Z\left(A A^{T}\right) Z^{T}}{(n-1)}=\frac{Z Y * Z^{T}}{(n-1)}
\end{gathered}
$$

where $Y$ is of dimension $\mathrm{m} \mathrm{m}$.

The first Principal Component retains the greatest amount of variation in the sample.

\subsection{Adaptive Neuro-Fuzzy Inference System (ANFIS)}

Adaptive neuro-fuzzy inference system is a hybrid algorithm that combines the fuzzy logic inference system and the neural network architecture. It comprises a fivelayer feed-forward structure which makes the ANFIS system have a good learning and inference capability [22]. Figure 3 shows the architecture of an ANFIS system having two inputs and one output and m-rule.

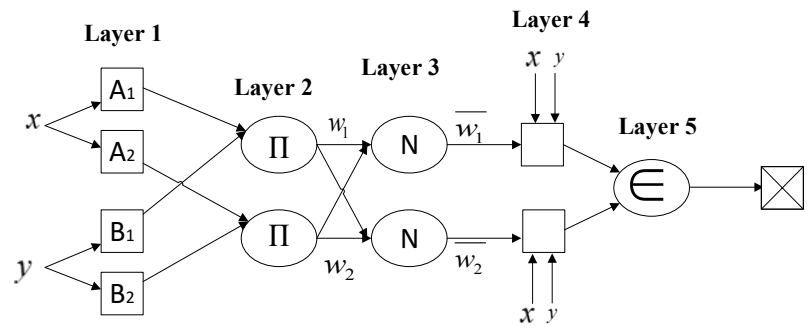

Figure 3. ANFIS Architecture

$x$ and $y$ are the inputs while $f$ is the output consisting of fixed nodes and adaptive nodes, represented by the circle and squares respectively. The Sugeno type fuzzy system is used where the fuzzy rules are of the form:

Rule 1:If $x$ is $A_{1}$ and $y$ is $B_{1}$, then $f_{1}=p_{1} x+q_{1} y+r_{1}$

Rule 2: If $x$ is $A_{2}$ and $y$ is $B_{2}$, then $f_{2}=p_{2} x+q_{2} y+r_{2}$

Layer 1: Every node $i$ in this layer is an adaptive node with a node function

$$
O_{l, i}=\mu_{A_{i}}(x) \text { for } i=1,2,
$$

or

$$
O_{l, i}=\mu_{B_{i-2}}(x) \text { for } i=3,4
$$

where 
$x=$ input to node $i$

$A_{i}=$ linguistic label associated with this node function.

$O_{i}=$ Membership function of $A_{i}$ and it specifies the

degree to which the given $x$ satisfies the quantifier $A_{i}$

Using the bell-shaped membership function $\mu_{A i}(x)$ with

a maximum equal to 1 and a minimum equal to 0 for the ANFIS architecture.

$$
\mu_{A i}(x)=\frac{1}{1+\left(\frac{x-c_{i}}{a_{i}}\right)^{2} b_{i}}
$$

where $\left\{a_{i}, b_{i}, c_{i}\right\}$ are the parameter set.

The bell-shaped functions vary as the values of these parameters change, thus exhibiting various forms of membership functions on the linguistic label $\boldsymbol{A}_{i}$. In fact, any continuous and piecewise differentiable functions, such as commonly used Gaussian, trapezoidal or triangular shaped membership functions are also qualified candidates for node functions in this layer.

Layer 2: Every node in this layer is a fixed node labelled $\Pi$. The output of this layer is the product of all the incoming signals as shown in equation;

$$
O_{2, i}=w_{i}=\mu_{A_{i}}(x) \cdot \mu_{B_{i}}(y),
$$

where $i=1,2$

Each node represents the firing strength of the rule.

Layer 3: Every node in this layer is a fixed node labelled $N$. The $i^{\text {th }}$ node calculates the ratio of the $i^{t h}$ rule's firing strength to the sum of all rule's firing strengths as expressed in equation 11 .

$$
O_{3, i}=\bar{w}_{i}=\frac{w_{i}}{w_{1}+w_{2}},
$$

where $i=1,2$

The outputs are called the normalised firing strengths.

Layer 4: Every node $i$ in this layer is an adaptive node with a node function:

$$
O_{4,1}=\overline{w_{i}} f_{i}=\overline{w_{i}}\left(p_{x}+q_{i} y+r_{i}\right)
$$

where

$\bar{w}_{i}$ is the normalised firing strength from the third layer.

$\left\{p_{i}, q_{i}, r_{i}\right\}$ is the parameter set of this node.

These are referred to as the consequent parameters.

Layer 5: The single node in this layer is also a fixed node labelled $\in$, which compute the overall output as the summation of all incoming signals.

$$
O_{5,1}=\sum \bar{w}_{i} f_{i}=\frac{\sum_{i} w_{i} f_{i}}{\sum_{i} w_{i}}
$$

The acquired data were transformed using the PCA technique and then normalised. The normalised principal components were used as the input of the ANFIS model while the output is the machine stator fault type. The fault conditions are classified into Normal operation, Yellow phase Inter-turn fault, Blue phase Inter-turn fault, Red phase inter-turn fault, Blue-red phase short, Yellow-red phase short and Blue-Yellow phase short circuit. The Adaptive Neuro-fuzzy inference system model generates the fault crisp rules that are used for further decision making. The ANFIS model was developed in MATLAB 2018 environment using the normalised principal components designated as PC1, PC2 and PC3. These inputs are transformed into triangular membership functions.

\section{RESULTS AND DISCUSSION}

\subsection{Feature Extraction of the Acquired Data}

The complete data set of the 482 acquired samples are compressed and de-noised using the PCA technique. The cumulative sum of the singular values is plotted on a stair plot to determine the extent of data represented by each principal component as shown in Figure 4.

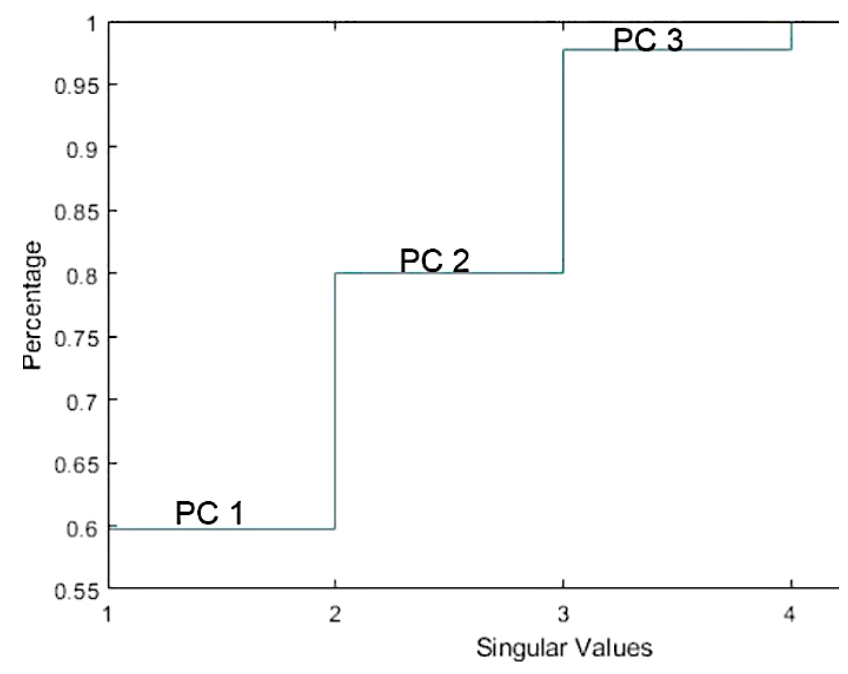

Figure 4. Plot of the cumulative sum

It is observed in Figure 4 that at PC 3, about $98 \%$ of the data are well-represented of the four generated principal components. therefore, only the first three PCs were used in this analysis. The fourth PC was regarded as the noise component of the data set because it contains the least representation of the original data with about $3 \%$. The new data set, which is a 482 by 3 matrix, is stored in the MATLAB variable "a". It is observed that the new compressed data matrix still has a set of 482 samples but this time with just three columns as against the original four columns of data. A sample of the new data set after PCA analysis under different conditions is shown in Table 1. 
Table 1. Data sample

\begin{tabular}{|l|l|l|l|}
\hline PC1 & PC2 & PC3 & Fault type \\
\hline-5.33195042361703 & 0.565523483972140 & 0.388550502174541 & 0 \\
-5.34039678693359 & 0.580911111917512 & 0.351515967349454 & 0 \\
-16.6064491875227 & -3.23372391773728 & -0.741168211557667 & 1 \\
-20.5845579569204 & -4.78556241769183 & -0.383872312149542 & 1 \\
33.19359872265 & 8.7649557286302 & -4.0030167696032 & 2 \\
\hline 32.87512721840 & 8.7091026657174 & -4.27213409205223 & 2 \\
-32.845804207343 & -5.2341578919178 & -1.53767698520850 & 3 \\
\hline-31.470006768467 & -5.8108128009463 & -2.74486315482396 & 3 \\
-25.382056664767 & -3.4195550211647 & 6.38902211074594 & 4 \\
\hline-24.410462279399 & -5.0105011182124 & 5.53028155617561 & 4 \\
-24.678168821763 & 1.5476498491282 & -4.63491902719935 & 5 \\
\hline-24.429225121400 & 1.8754267920136 & -4.80886474927425 & 5 \\
-27.627723257949 & 7.9641093113832 & 6.11176794977031 & 6 \\
\hline-27.089389885746 & 8.5056611804299 & 5.53374332167388 & 6 \\
\hline
\end{tabular}

\subsection{Feature Classification}

The training of the ANIFS was done using the grid partition method. The training data is divided into three sets, a set was used to train the ANFIS model, while another is used as the checking data and the final set is used as the testing data which were not part of the training data set. Different membership functions such as triangular, generalised bell, Gaussian curve and Gaussian curve 2 as shown in Tables 2 to 5 were used for the training of the ANFIS model.

Table 2. ANFIS 1, Experiment Result

\begin{tabular}{|c|c|c|c|c|c|c|c|c|c|}
\hline $\begin{array}{l}\text { ANFIS parameter } \\
\text { type }\end{array}$ & \multicolumn{9}{|c|}{ ANFIS (1) } \\
\hline Number of Inputs & \multicolumn{9}{|c|}{3} \\
\hline \begin{tabular}{l|} 
Membership \\
Functions type
\end{tabular} & \multicolumn{3}{|c|}{ Triangular-shaped } & \multicolumn{3}{|c|}{ Triangular-shaped } & \multicolumn{3}{|c|}{ Triangular-shaped } \\
\hline Number of MFs & $2,2,2$ & & & & $3,3,3$ & & & $4,4,4$ & \\
\hline Epoch number & 10 & 30 & 50 & 10 & 30 & 50 & 10 & 30 & 50 \\
\hline Number of Nodes & 34 & 34 & 34 & 78 & 78 & 78 & 158 & 158 & 158 \\
\hline $\begin{array}{l}\text { Number of Linear } \\
\text { Parameters }\end{array}$ & 8 & 8 & 8 & 27 & 27 & 27 & 64 & 64 & 64 \\
\hline $\begin{array}{l}\text { Number of } \\
\text { Nonlinear } \\
\text { Parameters }\end{array}$ & 18 & 18 & 18 & 27 & 27 & 27 & 36 & 36 & 36 \\
\hline $\begin{array}{l}\text { Total Number of } \\
\text { Parameters }\end{array}$ & 26 & 26 & 26 & 54 & 54 & 54 & 100 & 100 & 100 \\
\hline $\begin{array}{l}\text { Number of Fuzzy } \\
\text { Rules }\end{array}$ & 8 & 8 & 8 & 27 & 27 & 27 & 64 & 64 & 64 \\
\hline Training RMSE & $1.18 \mathrm{E}-06$ & $1.18 \mathrm{E}-06$ & $1.18 \mathrm{E}-06$ & $1.20 \mathrm{E}-05$ & $1.20 \mathrm{E}-05$ & $1.20 \mathrm{E}-05$ & $5.56 \mathrm{E}-05$ & $5.56 \mathrm{E}-05$ & $5.56 \mathrm{E}-05$ \\
\hline Checking RMSE & $1.63 \mathrm{E}-05$ & $1.63 \mathrm{E}-05$ & $1.63 \mathrm{E}-05$ & 3.44E-05 & \begin{tabular}{|l|}
$3.44 E-05$ \\
\end{tabular} & $3.44 \mathrm{E}-05$ & $1.67 \mathrm{E}-04$ & \begin{tabular}{|l|l|}
$1.67 E-04$ \\
\end{tabular} & $1.67 \mathrm{E}-04$ \\
\hline
\end{tabular}

Table 3. ANFIS 2, Experiment Result

\begin{tabular}{|c|c|c|c|c|c|c|c|c|c|}
\hline $\begin{array}{l}\text { ANFIS parameter } \\
\text { type }\end{array}$ & \multicolumn{9}{|c|}{ ANFIS (2) } \\
\hline Number of Inputs & \multicolumn{9}{|c|}{3} \\
\hline $\begin{array}{l}\text { Membership } \\
\text { Functions type } \\
\end{array}$ & \multicolumn{3}{|c|}{ Generalised Bell } & \multicolumn{3}{|c|}{ Generalised Bell } & \multicolumn{3}{|c|}{ Generalised Bell } \\
\hline Number of MFs & \multicolumn{3}{|c|}{$2,2,2$} & \multicolumn{3}{|c|}{$3,3,3$} & \multicolumn{3}{|c|}{$4,4,4$} \\
\hline Epoch number & 20 & 50 & 100 & 10 & 30 & 50 & 10 & 30 & 50 \\
\hline Number of Nodes & 34 & 34 & 34 & 78 & 78 & 78 & 158 & 158 & 158 \\
\hline $\begin{array}{l}\text { Num of Linear } \\
\text { Parameters }\end{array}$ & 8 & 8 & 8 & 27 & 27 & 27 & 64 & 64 & 64 \\
\hline $\begin{array}{l}\text { Num of Nonlinear } \\
\text { Parameters }\end{array}$ & 18 & 18 & 18 & 27 & 27 & 27 & 36 & 36 & 36 \\
\hline $\begin{array}{l}\text { Total Number of } \\
\text { Parameters }\end{array}$ & 26 & 26 & 26 & 54 & 54 & 54 & 100 & 100 & 100 \\
\hline $\begin{array}{l}\text { Number of Fuzzy } \\
\text { Rules }\end{array}$ & 8 & 8 & 8 & 27 & 27 & 27 & 64 & 64 & 64 \\
\hline Training RMSE & 0.015 & 0.003 & \begin{tabular}{|l|}
0.001 \\
\end{tabular} & 0.0004 & 0.0003 & 0.0003 & 0.0002 & 0.00008 & 0.00008 \\
\hline Checking RMSE & 0.008 & 0.004 & 0.0021 & 0.0011 & 0.0009 & 0.0009 & 0.0009 & 0.00029 & 0.00029 \\
\hline
\end{tabular}

Table 4. ANFIS 3, Experiment Result

\begin{tabular}{|c|c|c|c|c|c|c|c|c|c|}
\hline $\begin{array}{l}\text { ANFIS parameter } \\
\text { type }\end{array}$ & \multicolumn{9}{|c|}{ ANFIS (3) } \\
\hline Number of Inputs & \multicolumn{9}{|c|}{3} \\
\hline \begin{tabular}{|l|} 
Membership \\
Functions type
\end{tabular} & \multicolumn{3}{|c|}{ Gaussian Curve } & \multicolumn{3}{|c|}{ Gaussian Curve } & \multicolumn{3}{|c|}{ Gaussian Curve } \\
\hline Number of MFs & \multicolumn{3}{|c|}{$2,2,2$} & \multicolumn{3}{|c|}{$3,3,3$} & \multicolumn{3}{|c|}{$4,4,4$} \\
\hline Epoch number & 10 & 30 & 50 & 10 & 50 & 100 & 10 & 50 & 100 \\
\hline Number of Nodes & 34 & 34 & 34 & 78 & 78 & 78 & 158 & 158 & 158 \\
\hline $\begin{array}{l}\text { Num of Linear } \\
\text { Parameters }\end{array}$ & 8 & 8 & 8 & 27 & 27 & 27 & 64 & 64 & 64 \\
\hline $\begin{array}{l}\text { Num of Nonlinear } \\
\text { Parameters }\end{array}$ & 12 & 18 & 18 & 18 & 27 & 27 & 24 & 24 & 24 \\
\hline $\begin{array}{l}\text { Total Number of } \\
\text { Parameters }\end{array}$ & 20 & 26 & 26 & 45 & 54 & 54 & 88 & 88 & 88 \\
\hline $\begin{array}{l}\text { Number of Fuzzy } \\
\text { Rules }\end{array}$ & 8 & 8 & 8 & 27 & 27 & 27 & 64 & 64 & 64 \\
\hline \begin{tabular}{|l|l|} 
Training RMSE \\
\end{tabular} & 0.005 & 0.002 & 0.0013 & 0.0003 & 0.0003 & 0.0003 & 0.0001 & 5.8E-05 & 5.8E-05 \\
\hline Checking RMSE & 0.004 & \begin{tabular}{|l|l|}
0.002 \\
\end{tabular} & 0.0012 & 0.0009 & 0.0008 & 0.0008 & 0.0002 & 0.00014 & 0.00014 \\
\hline
\end{tabular}

Table 5. ANFIS 4, Experiment Result

\begin{tabular}{|c|c|c|c|c|c|c|c|c|c|}
\hline $\begin{array}{l}\text { ANFIS parameter } \\
\text { type }\end{array}$ & \multicolumn{9}{|c|}{ ANFIS (4) } \\
\hline Number of Inputs & \multicolumn{9}{|c|}{3} \\
\hline \begin{tabular}{l|} 
Membership \\
Functions type
\end{tabular} & \multicolumn{3}{|c|}{ Gaussian Curve 2} & \multicolumn{3}{|c|}{ Gaussian Curve 2} & \multicolumn{3}{|c|}{ Gaussian Curve 2} \\
\hline Number of MFs & \multicolumn{3}{|c|}{$2,2,2$} & \multicolumn{3}{|c|}{$3,3,3$} & \multicolumn{3}{|c|}{$4,4,4$} \\
\hline Epoch number & 10 & 30 & 50 & 10 & 30 & 50 & 10 & 30 & 50 \\
\hline Number of Nodes & 34 & 34 & 34 & 78 & 78 & 78 & 158 & 158 & 158 \\
\hline $\begin{array}{l}\text { Number of Linear } \\
\text { Parameters }\end{array}$ & 8 & 8 & 8 & 27 & 27 & 27 & 64 & 64 & 64 \\
\hline $\begin{array}{l}\text { Number of } \\
\text { Nonlinear } \\
\text { Parameters } \\
\end{array}$ & 24 & 24 & 24 & 36 & 27 & 27 & 24 & 24 & 24 \\
\hline $\begin{array}{l}\text { Total Number of } \\
\text { Parameters }\end{array}$ & 32 & 32 & 32 & 63 & 54 & 54 & 88 & 88 & 88 \\
\hline $\begin{array}{l}\text { Number of Fuzzy } \\
\text { Rules }\end{array}$ & 8 & 8 & 8 & 27 & 27 & 27 & 64 & 64 & 64 \\
\hline Training RMSE & 0.01 & 0.006 & 0.0056 & 0.0008 & 0.0006 & 0.0005 & 0.0006 & 0.00064 & 0.00064 \\
\hline Checking RMSE & 0.009 & 0.006 & 0.0062 & 0.0016 & 0.0009 & 0.0008 & 0.0018 & 0.00176 & 0.00176 \\
\hline
\end{tabular}

The developed models have exhibited substantial variation in their performances with respect to the evaluation criteria in terms of the number of membership functions (MFs), type of MFs and number of epochs. The RMSE values in ANFIS 1, Table 2, based on Triangularshaped were the lowest of the four ANFIS models and the lowest one in ANFIS 1 is the model with two membership functions. The training and checking error RMSE values are $1.1795 \times 10^{-6}$ and $1.6273 \times 10^{-5}$ respectively. The highest RMSE value recorded is in ANFIS 4, Table 5, based on Gaussian curve 2 membership function under the model with three membership functions. The training RMSE achieved is 0.00841 while the checking RMSE value is 0.001575

It is evident that the ANFIS model is highly sensitive to the number and type of MF used. The model performance does not necessarily improve with increasing the number of MFs but can cause model overfitting as evident in the experiments shown in Figure 5. Thus, the ANFIS model with a Triangular-shaped membership function with two membership and epoch numbers of 10,30 and 50 was used. The generated structure of ANFIS which consists of 34 nodes, 26 parameters, and 8 fuzzy rules as shown in Figure 6 while the surface diagram is shown in Figure 7. 


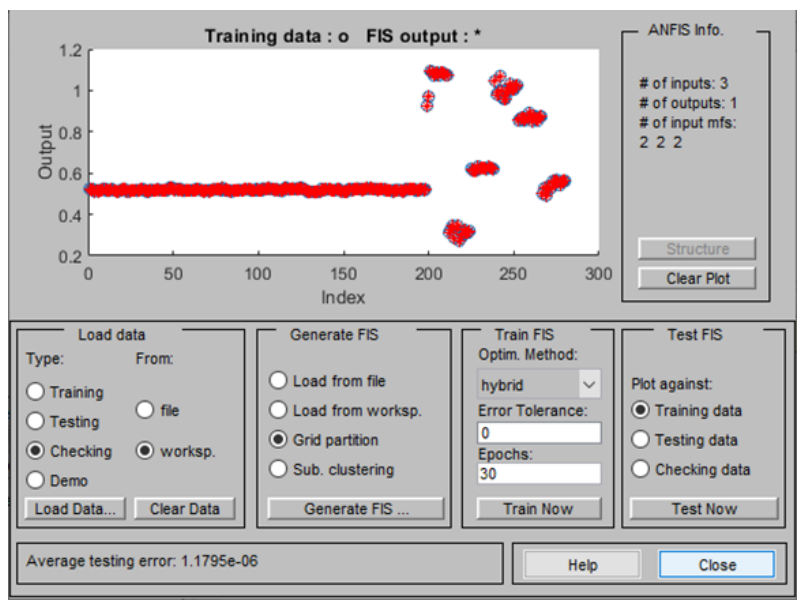

Figure 5. ANFIS training

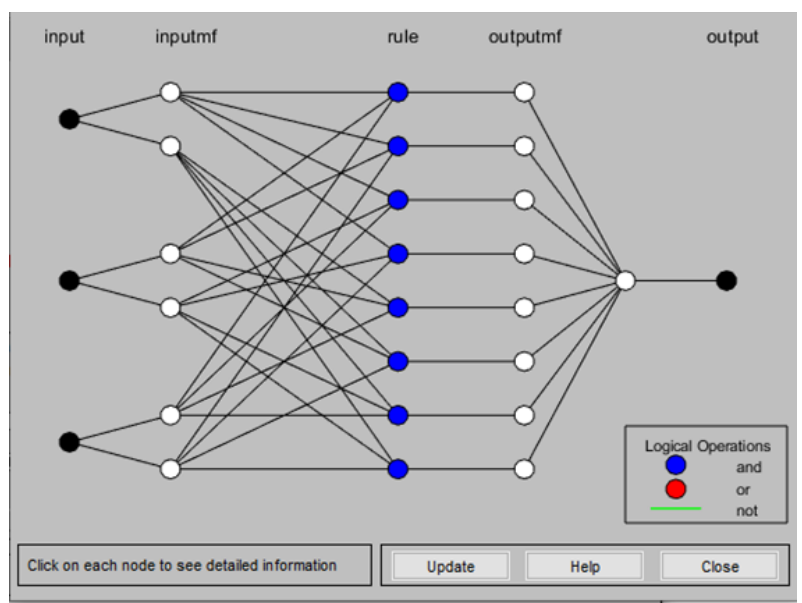

Figure 6. ANFIS Structure

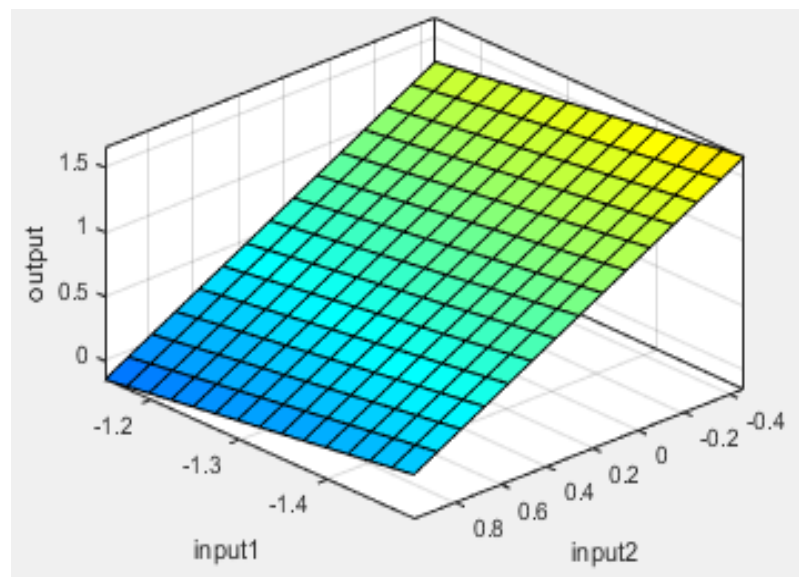

Figure 7. ANFIS surface plot

\subsection{Testing of ANFIS model for fault classification}

To further test the classification capability of the developed model, a group of testing data, consisting of 96 samples, which is not part of the training data and the checking data was used. The range of normalized values of each data under different conditions is shown in Table 6.
Table 6. Range of values for normalise data

\begin{tabular}{|c|c|c|c|c|}
\hline $\begin{array}{l}\text { Motor } \\
\text { Condition }\end{array}$ & $\mathrm{PCl}$ & PC2 & PC3 & Output \\
\hline $\begin{array}{l}\text { Normal } \\
\text { Operation }\end{array}$ & $(-1.4980)-(-1.4997)$ & $\begin{array}{l}0.4385- \\
0.4701\end{array}$ & $0.5102-0.5076$ & $0.5078-0.5272$ \\
\hline $\begin{array}{l}\text { Inter-turn } \\
\text { Yellow phase }\end{array}$ & $(-1.3922)-(-1.4122)$ & $\begin{array}{l}0.1353- \\
0.1503\end{array}$ & $0.9366-0.9846$ & $0.2722-0.3456$ \\
\hline $\begin{array}{l}\text { Inter-turn } \\
\text { Blue phase }\end{array}$ & $(-1.2311)-(-1.2470)$ & $\begin{array}{l}0.9618- \\
0.9861\end{array}$ & $\begin{array}{l}(-0.3468)-(- \\
0.3610)\end{array}$ & $0.6214-0.6320$ \\
\hline $\begin{array}{l}\text { Inter-turn } \\
\text { Red phase }\end{array}$ & $(-1.1347)-(-1.1998)$ & $\begin{array}{l}-0.0100- \\
0.4637\end{array}$ & $0.4685-0.5187$ & $0.9273-1.0943$ \\
\hline $\begin{array}{l}\text { Blue-Red } \\
\text { phase short }\end{array}$ & $(-1.3068)-(-1.3127)$ & $\begin{array}{l}0.4082- \\
0.5236\end{array}$ & $\begin{array}{l}(-0.01443)-(- \\
0.2209)\end{array}$ & $0.9592-1.0702$ \\
\hline $\begin{array}{l}\text { Yellow-Red } \\
\text { phase short }\end{array}$ & $(-1.2458)-(-1.2774)$ & $\begin{array}{l}(-0.3083)-(- \\
0.3661)\end{array}$ & $0.7220-0.7375$ & $0.8544-0.8921$ \\
\hline $\begin{array}{l}\text { Blue-Yellow } \\
\text { phase short }\end{array}$ & $(-1.4756)-(-1.4926)$ & $\begin{array}{l}0.6098- \\
0.6920\end{array}$ & $0.2394-0.3806$ & $0.4995-0.5673$ \\
\hline
\end{tabular}

Using the MATLAB rule viewer block, different input combinations can be inserted and the corresponding output of the trained system can be studied. The rule viewer block is used to revalidate our trained ANFIS model using different data from the train and checking data used initially. Table 7 shows the typical test data set used and the corresponding output.

Table 7. Validation of the ANFIS model with the test data set

\begin{tabular}{|l|l|l|l|l|l|}
\hline Condition & PC1 & PC2 & PC3 & $\begin{array}{l}\text { Original } \\
\text { Output }\end{array}$ & $\begin{array}{l}\text { Derived } \\
\text { output }\end{array}$ \\
\hline Normal & -1.49963395 & 0.46899401539 & 0.519399759 & 0.511240176 & 0.511 \\
\hline Normal & -1.49968191 & 0.47099539711 & 0.517466890 & 0.511219627 & 0.511 \\
\hline $\begin{array}{l}\text { Inter-turn } \\
\text { Red phase }\end{array}$ & -1.20158085 & -0.38223563184 & 0.512746981 & 1.071069509 & 1.071 \\
\hline $\begin{array}{l}\text { Inter-turn } \\
\text { Red phase }\end{array}$ & -1.19883849 & -0.38548603890 & 0.510076576 & 1.074247954 & 1.074 \\
\hline $\begin{array}{l}\text { Inter-turn } \\
\text { Yellow phase }\end{array}$ & -1.40119460 & 0.13942784481 & 0.963438555 & 0.298328200 & 0.298 \\
\hline $\begin{array}{l}\text { Inter-turn } \\
\text { Yellow phase }\end{array}$ & -1.39998194 & 0.14052724917 & 0.966765600 & 0.292689099 & 0.293 \\
\hline $\begin{array}{l}\text { Inter-turn } \\
\text { Blue phase }\end{array}$ & -1.24730093 & 0.95869558980 & -0.347376390 & 0.635981740 & 0.636 \\
\hline $\begin{array}{l}\text { Inter-turn } \\
\text { Blue phase }\end{array}$ & -1.25138879 & 0.94905552678 & -0.342603038 & 0.644936309 & 0.645 \\
\hline $\begin{array}{l}\text { Blue-red } \\
\text { phase short }\end{array}$ & -1.30885832 & 0.44841831895 & -0.167957384 & 1.028397395 & 1.03 \\
\hline $\begin{array}{l}\text { Blue-red } \\
\text { phase short }\end{array}$ & -1.30903805 & 0.43122524982 & -0.15908460 & 1.036897412 & 1.04 \\
\hline $\begin{array}{l}\text { Yellow-red } \\
\text { phase short }\end{array}$ & -1.26335990 & -0.33755719133 & 0.735231643 & 0.865685457 & 0.866 \\
\hline $\begin{array}{l}\text { Yellow-red } \\
\text { phase short }\end{array}$ & -1.27341723 & -0.31804798899 & 0.721999186 & 0.869466038 & 0.869 \\
\hline $\begin{array}{l}\text { Blue-yellow } \\
\text { phase short }\end{array}$ & -1.47863450 & 0.65684205036 & 0.261686481 & 0.560105974 & 0.56 \\
\hline $\begin{array}{l}\text { Blue-yellow } \\
\text { phase short }\end{array}$ & -1.48654594 & 0.6147359208 & 0.308911816 & 0.562898207 & 0.563 \\
\hline
\end{tabular}

Figure 8 shows the rule viewer of the model showing the output value from a sample input set from the test data set.

The rule viewer plot in Figure 8 was used to access the classification capability of the developed model. The figure shows the three input sets which are the three normalised PCs and as well as the output which is designated as the motor condition. The ranges of values for the three inputs and the expected output for each fault class are shown in Table 7. Taking a random input set from out data, for example, when PC1 is -1.246 , PC2 is -0.3661 and PC3 is 0.7197 which represents the Yellow-Red phase short circuit fault. When this input set is applied to the rule viewer as shown in Figure 8, the output, which is the motor condition gotten is 0.892 . This accurately falls within the range of the output of the intended fault which is the 
Yellow-Red phase short circuit fault. Similar tests for other fault types were also carried out as shown in Table 7 and a plot of the derived output and the original output from the data set is shown in Figure 9 for comparison.

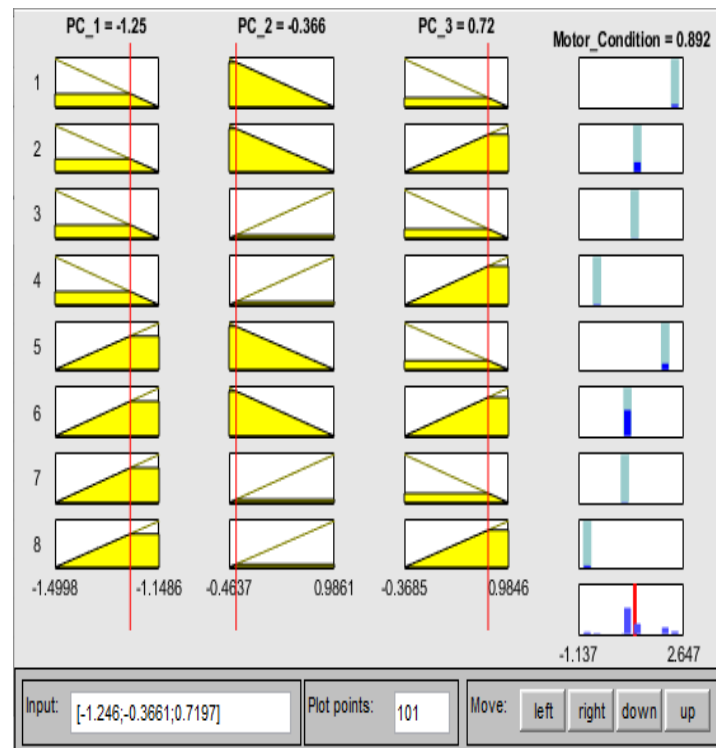

Figure 8. MATLAB rule viewer plot

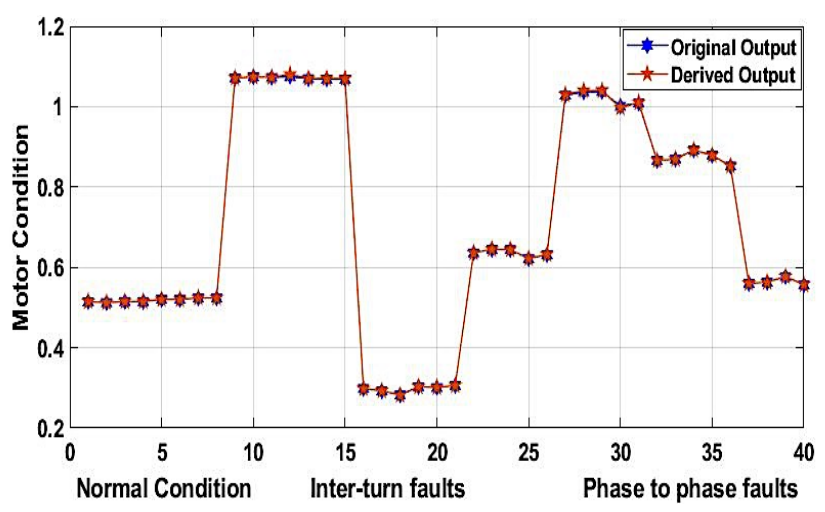

Figure 9. Model output plot

It is evident from the plot of the test data output and the original output of the classification model is of high accuracy which validates the result of the selected ANFIS model with a training error value of $1.1795 \mathrm{e}^{-6}$.

\section{CONCLUSION}

An intelligent induction motors stator fault classification is presented in this paper using the stator currents and vibration data. The model is a hybrid combination of PCA and ANFIS which classifies stator faults. The ANFIS model developed is based on triangular membership function with two membership functions. The accuracy of the model is over $99 \%$ as validated by MATLAB/Simulink simulation.

\section{REFERENCES}

[1] A. Siddique, G. S. Yadava, and B. Singh, "A review of stator fault monitoring techniques of induction motors," IEEE Transactions on Energy Conversion, vol. 20, no. 1. pp. 106-114, 2005.

[2] D. Ibrahim, "An Overview of Soft Computing," Procedia Comput. Sci., vol. 102, no. August, pp. 3438, 2016.

[3] M. Subha, N. S. Kumar, and K. S. K. Veni, "Artificial Intelligence Based Stator Winding Fault Estimation in Three-phaseInduction Motor," Proc. 2nd Int. Conf. Electron. Commun. Aerosp. Technol. ICECA 2018, no. Iceca, pp. 1929-1933, 2018.

[4] P. V. Jover Rodríguez and A. Arkkio, "Detection of stator winding fault in induction motor using fuzzy logic," Appl. Soft Comput. J., vol. 8, no. 2, pp. 11121120, 2008.

[5] J. F. Martins, V. F. Pires, and A. J. Pires, "Unsupervised Neural-Network-Based Algorithm for an On-Line Diagnosis of Three-Phase Induction Motor Stator Fault," IEEE Trans. Ind. Electron. VOL. 54, NO. 1, Febr. 2007, vol. 54, no. 1, pp. 259264, 2007.

[6] M. B. K. Bouzid, G. Champenois, N. M. Bellaaj, L. Signac, and K. Jelassi, "An effective neural approach for the automatic location of stator interturn faults in induction motor," IEEE Trans. Ind. Electron., vol. 55, no. 12, pp. 4277-4289, 2008.

[7] M. S. Yilmaz and E. Ayaz, "adaptive neuro-fuzzy inference system for bearing fault detection in induction motors using temperature, current, vibration data," pp. 1140-1145, 2009.

[8] Y. Lei, Z. He, Y. Zi, and Q. Hu, "Fault diagnosis of rotating machinery based on multiple ANFIS combination with GAs," Mech. Syst. Signal Process., vol. 21, no. 5, pp. 2280-2294, 2007.

[9] R. N. Dash and B. Subudhi, "Stator inter-turn fault detection of an induction motor using neuro-fuzzy techniques," Arch. Control Sci., vol. 20, no. 3, pp. 363-376, 2010.

[10] G. Jose and V. Jose, "Fuzzy logic based Fault Diagnosis in Induction Motor," Natl. Conf. Technol. Trends, no. 14, pp. 150-156, 2013.

[11] B. Djamila, B. Tahar, and M. Hichem, "Vibration for detection and diagnosis bearing faults using adaptive neurofuzzy inference system," J. Electr. Syst., vol. 14, no. 1, pp. 95-104, 2018.

[12] M. M. Mijwel, "Artificial Neural Networks Advantages and Disadvantages | Maad M. Mijwel | Pulse | LinkedIn," no. January, 2018.

[13] A. Widodo, B. S. Yang, and T. Han, "Combination of independent component analysis and support vector machines for intelligent faults diagnosis of induction motors," Expert Syst. Appl., vol. 32, no. 2, pp. 299-312, 2007.

[14] B. S. Yang and K. J. Kim, "Application of DempsterShafer theory in fault diagnosis of induction motors using vibration and current signals," Mech. Syst. Signal Process., vol. 20, no. 2, pp. 403-420, 2006.

[15] K. Warne, G. Prasad, N. H. Siddique, and L. P. Maguire, "Development of a hybrid PCA-ANFIS measurement system for monitoring product quality in the coating industry," Conf. Proc. - IEEE Int. Conf. Syst. Man Cybern., vol. 4, pp. 3519-3524, 2004.

[16] D. Bouayad and F. Emeriault, "Modeling the relationship between ground surface settlements induced by shield tunneling and the operational and 
geological parameters based on the hybrid PCA/ANFIS method," Tunn. Undergr. Sp. Technol., vol. 68, no. November 2016, pp. 142-152, 2017.

[17] M. N. M. Salleh, N. Talpur, and K. Hussain, "Adaptive neuro-fuzzy inference system: Overview, strengths, limitations, and solutions," Lect. Notes Comput. Sci. (including Subser. Lect. Notes Artif. Intell. Lect. Notes Bioinformatics), vol. 10387 LNCS, no. November 2018, pp. 527-535, 2017.

[18] A. I. Abdullateef, O. S. Fagbolagun, and M. F. Sanusi, "Data Acquisition of Current and Vibration Data for Rewound Burnt Three-Phase Induction Motor," J. Appl. Sci. Environ. Manag., vol. 23, no. 12, pp. 2177-2183, 2019.
[19] I. Jolliffe, "Principal component analysis. Springer Series in Statistics," Encycl. Stat. Behav. Sci., p. 487, 2002.

[20] P. Lindsey, "Book review: BOOK REVIEW," Austral Ecol., vol. 28, no. 4, pp. 468-469, 2003.

[21] S. Sehgal, H. Singh, M. Agarwal, and V. B. and Shantanu, "Data analysis utilizing principal component analysis," Int. Conf. Med. Imaging, mHealth Emerg. Commun. Syst., pp. 45-48, 2014.

[22] S. Altug, M. Y. Chow, and H. Joel Trussell, "Fuzzy inference systems implemented on neural architectures for motor fault detection and diagnosis," IEEE Trans. Ind. Electron., vol. 46, no. 6, pp. 1069-1079, 1999. 